\title{
PENDIRI KUALA LUMPUR
}

\section{Oleh Shohibul Anshor Siregar}

Penggunaan kata "founder" dalam sejarah yang dituliskan oleh pihak Barat adalah sesuatu yang amat bermasalah. Tak dapat tidak, kata itu telah amat kerap digunakan untuk maksud tertentu pada zaman penjajahan.

Christopher Columbus misalnya telah dinyatakan sebagai discover of America. Captain James Cook the founder of Australia, the founder of Singapore adalah Sir Thomas Stamford Raffles.

Di Indonesia ada sejenis bunga yang unik dan sangat indah serta berukuran besar, dan oleh penjajah disebut pertamakalinya ditemukan oleh Rafless hingga dinamakan Raflesia.

Semua klaim seperti itu benar-benar menggap rendah dan menyepelekan komunitas dan kebudayaan serta pengetahuan, apalagi sejarah, orang-orang lokal (jajahan) yang menjadi pemilik sebenarnya dari aset-aset itu. Betapa pun sangat pahit, itu adalah sebuah kenyataan yang dilatari kecongkakan tak berdasar.

Negeri-negeri bekas jajahan hingga kini masih belum selesai dengan dampak perlakuan penjajah itu. Sebagai suatu contoh, Anthony Reid misalnya, pada tahun 2016 yang lalu, memberi pernyataan mengejutkan melalui makalahnya "Is There A Batak History". Makalah ini memberi gugatan terhadap segala yang ditulis oleh orang Barat bekas penjajah dan orangorang yang kemudian mengikutinya di kemudian hari, tentang siapa sebetulnya orang Batak itu. Malangnya akses untuk sumber-sumber data pun tak begitu mudah, karena telah mereka bawa ke negerinya (penjajah) dengan tanpa izin pemilik sama sekali.

Selain itu masalah bahasa juga membuat usaha lebih mengenali diri sendiri menjadi lebih sulit bagi negara-negara bekas jajahan itu. Pemerintah negara-negara bekas jajahan seperti Indonesia pun seolah merasa belum memiliki urusan mengenai hal penting seperti itu. Bayangkanlah sebuah negara-bangsa dengan sebuah ketak-jelasan sejarah. Pahit itu.

Seorang intelektual dari etnis Mandailing yang tinggal di Malaysia, Abdur-Razzaq Lubis, tanggal 7 April 2018 lalu meluncurkan bukunya berjudul "Sutan Puasa: Founder of Kuala Lumpur". Buku itu hadir dengan sebuah misi, yakni meruntuhkan mitos lama tentang pendiri Kuala Lumpur. Dalam buku-buku sejarah Malaysia umumnya ada dua nama legendaris yang selalu dihubungkan dengan pendirian kota Kuala Lumpur. Mereka ialah Raja Abdullah, bangsawan yang berasal dari Bugis, yang dulu pernah menjadi pemimpin di Klang, dan Yap Ah Loy, Kapitan terakhir (ketiga) Cina yang pernah bertugas di tempat yang belakangan dikenal dengan nama Kuala Lumpur.

Para pemandu turis kota di Kuala Lumpur sendiri hingga hari ini umumnya lebih percaya dan bersikukuh bahwa pendiri Kuala Lumpur itu adalah Yap Ah Loy. Bukan Raja Abdullah dan sama sekali tak mengenal nama lain. Mereka mendapat asupan informasi dari sumber-sumber negara, tentu saja. 
Memang, awalnya Yap Ah Loy inilah yang telah dinyatakan sebagai pendiri Kuala Lumpur. Tetapi belakangan terasa ada ketidakmasukakalan di sini. Itulah yang dijawab oleh buku Abdur-Razaq Lubis.

Misi buku "Sutan Puasa: Founder of Kuala Lumpur" setebal 615 halaman, seberat lebih kurang 2 kilogram yang kaya dengan illustrasi, gambar dan foto (144 buah), 5 tabel, 16 uraian saripati (box) dan dengan 2362 catatan kaki, ini adalah mengungkapkan kepalsuankepalsuan mitos dengan data-data akurat. Memang sudah cukup lama pertanyaan tentang siapa sebenarnya pendiri kota Kuala Lumpur diwarnai dengan penuh keraguan kritis. Ketidakjelasan itu tentu sekaligus merefleksikan ketidakjelasan lainnya, yakni kapan kota Kuala Lumpur, ibu kota Malaysia itu, berdiri. Tentang hal ini Abdur-Razzaq Lubis pernah berkata: "Bila dan siapa sebenarnya yang membuka Kuala Lumpur masih menjadi soalan yang terbuka".

Sejumlah intelektual Malaysia juga ikut andil dalam pencarian kebenaran sejarah Kuala Lumpur. Prof. Emeritus Tan Sri Dato' Dr. Khoo Kay Kim, pakar sejarah dari Universitas Malaya dan Dato' Ar. Haji Hajeedar Abdul Majid, seorang arsitek yang berkedudukan sebagai Majelis Warisan Kebangsaan Malaysia, dalam sebuah seminar yang diselenggarakan bulan Juli tahun lalu, mengemukakan bantahan atas status Yap Ah Loy sebagai pendiri Kuala Lumpur. Seminar yang bertajuk “Apakah Kuala Lumpur dibuka oleh Yap Ah Loy?” itu diselenggarakan di Universitas Malaya.

Dari seminar ini diperoleh kesimpulan bahwa memang Yap Ah Loy itu adalah salah seorang di antara 3 Kapitan Cina di Kuala Lumpur, dan sebetulnya, sebagaimana telah dikemukakan di atas, secara berurutan dia adalah Kapitan Cina yang ketiga (terakhir). Tentulah jika ada salah seorang di antara ketiga Kapitan Cina ini yang harus diyakini sebagai pendiri Kuala Lumpur, orangnya bukanlah Kapitan Yah Ah Loy yang kedudukannya hanya meneruskan kekapitanan dua Kapitan Cina yang berkuasa sebelumnya.

Yap Ah Loy pertama kali datang ke Melaka pada tahun 1854 pada usia 17 tahun. Kapten Cina nomor dualah yang membawanya ke Kuala Lumpur dan barulah pada 1868 dilantik menjadi Kapten Cina ke 3. Memang pada tahun 1869 Yap Ah Loy ‘ditabalkan' sebagai pendiri Kuala Lumpur. Setelah itu, juga di bawah kontroversi yang beraroma politik dan kekuasaan, Raja Abdullah pernah secara resmi dikukuhkan sebagai pendiri Kuala Lumpur yang sebenarnya. Ini sekaligus menolak status Yap Ah Loy. Raja Abdullah yang dalam banyak sumber dikatakan raja Melayu itu sebenarnya adalah raja Bugis yang datang ke Kuala Lumpur setelah perantauannya ke Riau (Indonesia yang sekarang).

Kontroversi sejarah cukup lama berayun di antara pengakuan terhadap Raja Abdullah dan Yap Ah Loy sebagai pendiri legendaris kota Kuala Lumpur. Namun pemeriksaan yang lebih seksama yang dilakukan oleh Abdur-Razaq Lubis mengungkapkan bahwa mitos-mitos pendiri Kuala Lumpur telah menghilangkan bab paling awal dari pembuktian, itulah sisi gelap atau yang digelapkan tentang data sebenarnya mengenai keberadaan dan peran yang tak terbantahkan Sutan Puasa (Lubis) yang ternyata mendahului yang lain. 
Ditegaskan oleh Abdur-Razaq Lubis, Kuala Lumpur atau Pangkalan Lumpur atau Pangkalan Bustak, adalah pos perdagangan orang-orang Mandailing persis di pertemuan sungai Klang dan Gombak yang kini menjadi tempat berdirinya sebuah masjid besar (masjid Jamik). Di sinilah titik pengendalian jalur darat dan sungai di lembah Klang bagian atas yang berkat kepemimpinan visioner Sutan Puasa tempat itu akhirnya berkembang menjadi kota multibudaya, menarik para penambang dan pedagang dari Sumatera (Nusantara) dan Hakka (Cina).

Sutan Puasa yang pengusaha pertambangan, pedagang timah dan pelopor pertanian di Malaysia itu adalah salah seorang tokoh paling terkemuka dari para bangsawan Mandailing yang beremigrasi ke Malaya antara lain karena Perang Padri (1803-1845). Satu hal yang sudah diketahui pasti bahwa sebelum tokoh-tokoh lain (termasuk Raja Abdullah dan Yap Ah Loy) datang, bermukim dan berusaha di Kuala Lumpur pada 1857, Sutan Puasa sudah terlebih dahulu tinggal di sana. Sutan Puasa, anak raja Mandailing itu, tercatat memiliki inisiatif untuk tidak sekadar berhubungan dengan para pedagang Tionghua suku Haka seperti Hiu Siew dan Ah Sze Keledek, sekitar tahun 1859, malah mengajak orang-orang ini untuk tinggal berdekatan kampung, yang diduga keras terkait dengan usaha tambang bijih timah.

Meski begitu tentulah pelurusan sejarah ini tak perlu dibayangkan akan berimplikasi atas sebuah klaim tentang siapa pemilik Kuala Lumpur. Tidaklah dengan pelurusan sejarah ini akan ada gelombang besar orang Mandailing dari Indonesia yang akan berjuang secara hukum apalagi melakukan invasi untuk menyatakan pengakuan atas kepemilikannya yang sah atas Kuala Lumpur. Urusannya hanya sebatas pemberian hak kepada yang mustahak dan menjernihkan kabut-kabut mitos yang menyelimuti sejarah selama ini.

Namun reaksi terhadap Abdur-Razaq Lubis muncul dari berbagai pihak. Tentu saja AbdurRazaq Lubis sudah sangat siap untuk menghadapi itu, karena baginya kebenaran hanya akan dibuktikan oleh data dan sesiapa yang memiliki data berbeda untuk membantah tentu saja ia akan sangat terbuka untuk dikonfrontasikan.

Tarik-menarik kepentingan dan pengaruh di antara kelompok-kelompok etnis, yang sekaligus juga menggambarkan dominasi di Negeri itu, terutama dari segi ekonomi dan politik, menjadi sesuatu yang benar-benar mempersulit ketibaan pada suatu kesimpulan yang terterima secara lebih luas. Sejarah penjajahan negeri itu ikut memperkeruh keadaan, tentu saja.

Mantan Perdana Menteri Malaysia yang pada pemilu bulan depan akan tampil kembali sebagai calon perdana menteri, belum lama ini berkata bahwa Inggeris sebetulnya ingin orang Malaysia tidak tahu sejarahnya sendiri. Pada zamannya sebagai pelajar, sekolah-sekolah Inggeris tak memberi kesempatan kepada generasi muda untuk mengetahui sejarah negerinya. Tidak ada pelajaran sejarah bangsa. Inggeris hanya ingin menorehkan sebuah doktrin yang tak boleh digugat bahwa Malaysia adalah negeri yang berbahagia sebab ia tak memiliki sejarah. Cukup sampai di situ.

Tentu kita punya sejarah, tegas Mahathir Mohammad. Termasuk bagaimana kedatangan Inggeris ke Malaysia, bagaimana dan dengan cara apa mereka mendapatkan Pulau Pinang dan begitu pula Singapura. Semuanya itu adalah bagian dari sejarah. Tetapi, sepanjang 
ingatan Mahathir Mohammad, melalui pendidikan sebetulnya Inggeris ingin agar Malaysia benar-benar yakin tak memiliki sejarah. Karena itu, menurutnya, ada hal yang berbeda dibanding di negara-negara lain yang terjajah pada masa lalu. Sebagai contoh, di Indonesia sudah ada gerakan sistematis untuk melawan penjajahan, begitu juga di India. Pada saat yang sama di Malaysia tak berfikir tentang apa-apa. Kita hanya puas menyanyikan "God Save the Queen", ucap Mahathir Mohammad prihatin.

Penulis dosen FISIP UMSU. Koordinator Umum Pengembangan Basis Sosial Inisiatif \& Swadaya ('nBASIS) 